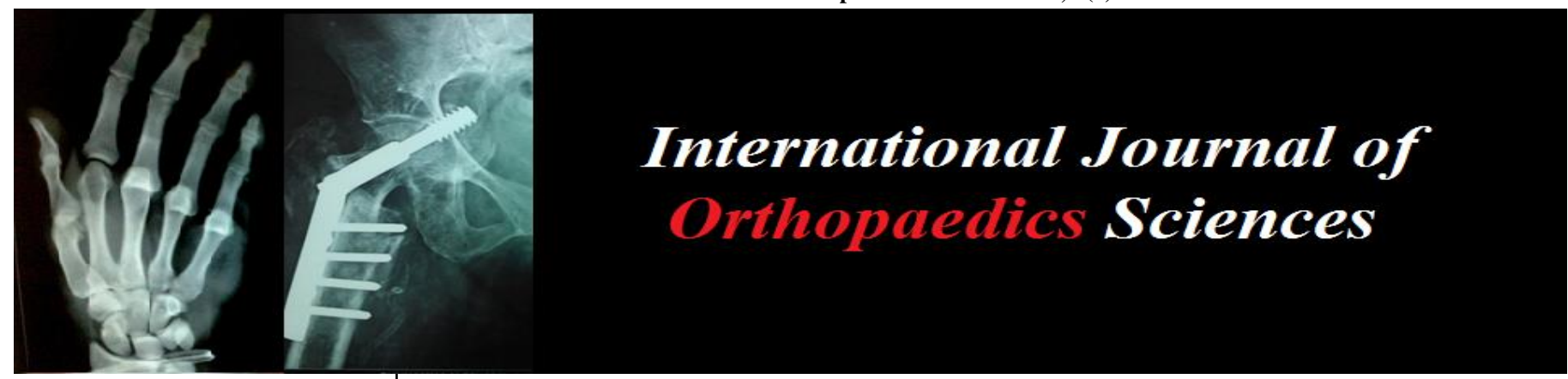

E-ISSN: 2395-1958

P-ISSN: 2706-6630

IJOS 2021; 7(2): 503-505

(C) 2021 IJOS

www.orthopaper.com

Received: 12-02-2021

Accepted: 21-03-2021

Amit J Patel

Professor, Department of

Orthopedics, Pramukhswami

Medical College, Karamsad,

Gujarat, India

Mrudev V Gandhi

Department of Orthopedics,

Pramukhswami Medical College,

Karamsad, Gujarat, India

Utsav V Patel

Department of Orthopedics,

Pramukhswami Medical College,

Karamsad, Gujarat, India
Corresponding Author:

Mrudev V Gandhi

Department of Orthopedics,

Pramukhswami Medical College,

Karamsad, Gujarat, India

\section{A simple screening procedure could identify Indian patients with early cognitive impairment and its implications for the management of geriatric hip fracture}

\author{
Amit J Patel, Mrudev V Gandhi and Utsav V Patel
}

DOI: https://doi.org/10.22271/ortho.2021.v7.i2g.2669

Abstract

Background: Dementia is one of the most common and cognitive impairments growing over the globe. It encompasses a wide range of other neurodegenerative disorders with the symptoms such as loss of memory, inability in carrying out everyday activities, a decline in the brain function activities, and perplexity. However, it has been identified that there is an absolute lack of treatment modalities for dementia, but the early diagnosis plays an important role in identifying the cognitive impairment in the asymptomatic phase itself. It helps in preventing the disease from reaching a further complicated stage.

Aim: To assess the impact of cognitive impairment screening on the management of geriatric hip fractures.

Methods: It was an observational study carried out at the Shree Krishna Hospital, Karamsad for a period of June, 2018 to May, 2020. Two hundred sixty patients were included in the study. The patients were divided into three groups, namely hemiarthroplasty (HA), Total Hip Arthroplasty (THA), hemiarthroplasty in patients with known dementia (HAd).

Result: The study showed male preponderance in the study, and the majority of the patients were above 80 years of age. There was a significant difference in the patients who can perform their grocery or medication independently and not independently with respect to MMSE. However, there was no statistically significant difference in Hip Harris Score. There was a statistically significant difference among the three groups regarding the intraoperative blood, operation duration, hospital stay, ICU postoperative, in-hospital details.

Conclusion: In light of the above literature, it was found that hip fractures and cognitive impairment were closely related. There are many risk factors of hip fracture, which are aggravated due to the late diagnosis of cognitive impairment. The incidence of hip fracture among patients suffering from dementia was much higher as compared to normal patients.

Keywords: Multi-morbidity, cognitive impairment, geriatric hip fracture

\section{Introduction}

Dementia is one of the most common and cognitive impairments growing over the globe. It encompasses a wide range of other neurodegenerative disorders with the symptoms such as loss of memory, inability in carrying out everyday activities, a decline in the brain function activities, and perplexity ${ }^{[1]}$. However, it has been identified that there is an absolute lack of treatment modalities for dementia, but the early diagnosis plays an important role in identifying the cognitive impairment in the asymptomatic phase itself. It helps in preventing the disease from reachinga further complicated stage ${ }^{[2]}$.

Dementia and hip fractures are the two most predominantly occurring conditions addressed among the patients with the growing age ${ }^{[3]}$. It has been identified that the prevalence rate is increasing with the advancement of age. Starting from $3.0 \%$ in the people aged between $65-74$ years and going to $18.0 \%$ in the patients aged between $75-85$ years of age ${ }^{[4]}$. Also, it has been observed that this incidence rate is as high as $48 \%$ among the older patients aged above 85 years ${ }^{[5]}$. Similarly, it has been witnessed that the incidence of hip fractures among patients aged above 65 years is nearly $60 \%$. It has also been witnessed that the rate of mortality among hip fracture patients is relevantly high as compared to any other ailment ${ }^{[6]}$. 
Furthermore, it has been observed that the patients suffering from cognitive impairment are at a higher risk of hip fractures as compared to those who are cognitively sound ${ }^{[7]}$. As dementia mainly occurs from Alzheimer disease, Parkinson
Disease, and vascular disease that result in visual hallucination, disturbed consciousness levels, and frequent falls. These all factors contribute a great deal to the increased intensity of hip fractures ${ }^{[8]}$.

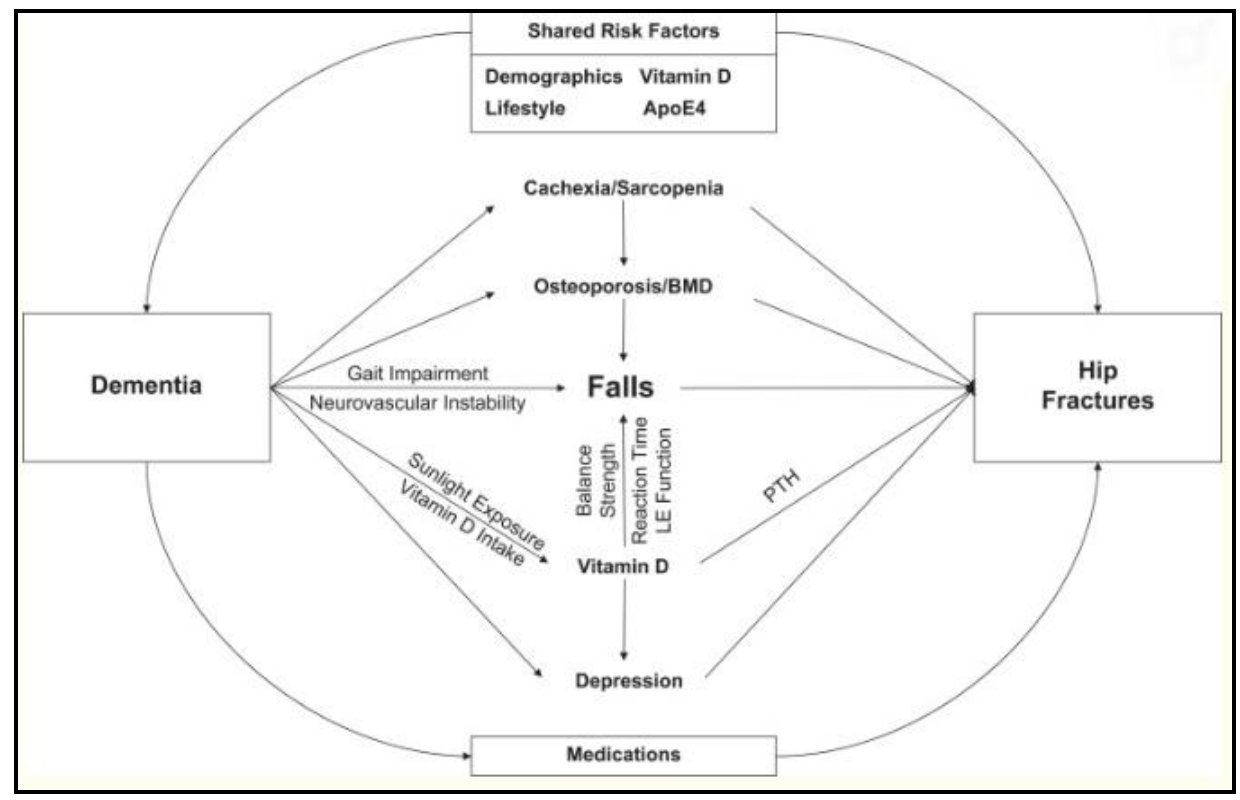

Fig 1: Pathogenic framework for dementia and hip fracture ${ }^{[7]}$

The lack of exposure to the psychological tests and the lack of early recognition has resulted in increased hospital stay among patients with cognitive impairment undergoing hip fracture treatment ${ }^{[9]}$.

\section{Aim}

To assess the impact of cognitive impairment screening on the management of geriatric hip fractures.

\section{Material and Methods}

It was an observational study carried out at the Shree Krishna Hospital, Karamsad for a period of June, 2018 to May, 2020. Two hundred sixty patients were included in the study. The patients were divided into three groups, namely hemiarthroplasty (HA), Total Hip Arthroplasty (THA), hemiarthroplasty in patients with known dementia (HAd).

\section{Results}

Table 1: Summary of Patient Characteristics Included in the Clinical Analysis

\begin{tabular}{|c|c|c|c|}
\hline Patient characteristics & THA & HA & HAd \\
\hline BMI & 26 & 26 & 22 \\
\hline Age & 82 & 84 & 90 \\
\hline Gender & & & \\
\hline Male & 20 & 20 & 12 \\
\hline Female & 80 & 78 & 50 \\
\hline ASA score average & 2 & 3 & 4 \\
\hline 1 & - & - & - \\
\hline 2 & 59 & 21 & 7 \\
\hline 3 & 37 & 67 & 47 \\
\hline 4 & 3 & 10 & 9 \\
\hline Follow-up & 45 & 8 & 4 \\
\hline
\end{tabular}

The above table showed the patient characteristics. The study showed male preponderance in the study, and the majority of the patients were above 80 years of age.
Table 2: Ambulatory Status and Neuropsychological Assessment of Patients Separated to a Group Based on Their Inability to Perform Their Grocery Shopping and/or Prepare Their Medications Independently

\begin{tabular}{|c|c|c|c|}
\hline Subtest & Not Independent & Independent & P-value \\
\hline MMSE & -2.7 & -0.5 & $<0.05$ \\
\hline Harris Hip Score & 76 & 84 & $>0.05$ \\
\hline
\end{tabular}

The above table showed that there was a significant difference in the patients who can perform their grocery or medication independently and not independently with respect to MMSE. However, there was no statistically significant difference in Hip Harris Score.

Table 3: Peri-operative Parameters

\begin{tabular}{|c|c|c|c|c|}
\hline Peri-operative parameters & THA & HA & Had & p-value \\
\hline Intraoperative blood loss (ml) & 392 & 239 & 199 & $<0.05$ \\
\hline Operation duration (min) & 100 & 82 & 89 & $<0.05$ \\
\hline Hospital stay (d) & 7 & 9 & 8 & $>0.05$ \\
\hline ICU postoperative (n) & 4 & 13 & 10 & $<0.05$ \\
\hline Inhospital deaths (n) & 3 & 5 & 12 & $<0.05$ \\
\hline
\end{tabular}

The above table showed that there was a statistically significant difference among the three groups regarding the intraoperative blood, operation duration, hospital stay, ICU postoperative, in-hospital details.

It was also found in the current study that patients with dementia and on treatment were more prone to falls that resulted in increased chances of hip fractures. Cholinesterase inhibitors are often prescribed for Alzheimer disease, which results in increasing the scope of syncope that, in turn,results in fall and hip fractures. The risk factors of hip fracture included neurovascular instability, falls, vitamin D deficiency, osteoporosis, decreased bone density, and depression. These are all the factors generated by cognitive impairment as well. Therefore, early diagnosis might also improve the management scheme as they reduce the risk of hip fractures and also reduces postoperative complications as well. 


\section{Discussion}

It was identified in the current study that there was no statistically significant difference among the different groups regarding the age group. Similar results were found in the study of Schaller et al. (2012) ${ }^{[10]}$. In the current study, it was found that there was no significant difference among the different groups regarding the mortality. Similarly, according to the study of Baker et al. (2006) ${ }^{[11]}$, there was no statistically significant difference between the two groups. In the current study, it was found that the postoperative complications were low as the rate of dislocation was quite low. It was showed that the in geriatric hip fractures THA is the aptest treatment mechanism, but it showed a higher rate of dislocation as compared to the patients treated with HA. On the contrary, Liao et al. (2012) ${ }^{[12]}$ found higher rates of dislocation and complication postoperatively. In the current study, it was found that cognitive impairment was closely related to hip fractures. Similar results were obtained in the study of Gill et al., (2009) ${ }^{[13]}$.

\section{Conclusion}

In light of the above literature, it was found that hip fractures and cognitive impairment were closely related. There are manyrisk factors of hip fracture, which are aggravated due to the late diagnosis of cognitive impairment. The incidence of hip fracture among patients suffering from dementia was much higher as compared to normal patients.

\section{References}

1. Evans DA, Funkenstein HH, Albert MS et al. Prevalence of Alzheimer's disease in a community population of older persons. Higher than previously reported. JAMA 1989;262(18):2551-2556.

2. Guo Z, Viitanen M, Winblad B. Low blood pressure and five-year mortality in a Stockholm cohort of the very old: possible confounding by cognitive impairment and other factors. Am J Public Health 1997;87(4):623-628.

3. Braithwaite RS, Col NF, Wong JB. Estimating hip fracture morbidity, mortality and costs. J Am Geriatr Soc 2003;51(3):364-370.

4. Brauer CA, Coca-Perraillon M, Cutler DM, Rosen AB. Incidence and mortality of hip fractures in the United States. JAMA 2009;302(14):1573-1579.

5. Leslie WD, O'Donnell S, Jean $\mathrm{S}$ et al. Trends in hip fracture rates in Canada. JAMA 2009;302(8):883-889.

6. Magaziner J, Hawkes W, Hebel JR et al. Recovery from hip fracture in eight areas of function. J Gerontol A Biol Sci Med Sci 2000;55(9):M498-M507

7. Friedman SM et al. Dementia and Hip Fractures. Geriatr Orthop Surg Rehabil 2010;1(2):52-62.

8. Nevitt MC, Cummings SR, Hudes ES. Risk factors for injurious falls: a prospective study. J Gerontol 1991;46(5):M164-M170

9. Camicioli R, Licis L. Motor impairment predicts falls in specialized Alzheimer care units. Alzheimer Dis Assoc Disord 2004;18(4):214-218

10. Schaller F, Sidelnikov E, Theiler R, Egli A, Staehelin $\mathrm{HB}$, Dick $\mathrm{W}$ et al. Mild to moderate cognitive impairment is a major risk factor for mortality and nursing home admission in the first year after hip fracture. Bone 2012;51:347e52.

11. Baker RP, Squires B, Gargan MF, Bannister GC. Total hip arthroplasty and hemiarthroplasty in mobile, independent patients with a displaced intracapsular fracture of the femoral neck. A randomized, controlled trial. J Bone Joint Surg Am 2006;88:2583e9.

12. Liao L, Zhao J, Su W, Ding X, Chen L, Luo S. A metaanalysis of total hip arthroplasty and hemiarthroplasty outcomes for displaced femoral neck fractures. Arch Orthop Trauma Surg 2012;132:1021e9.

13. Gill SS, Anderson GM, Fischer HD, Bell CM, Li P, Normand SL et al. Syncope and its consequences in patients with dementia receiving cholinesterase inhibitors: a population-based cohort study. Arch Intern Med 2009;169(9):867-73. 